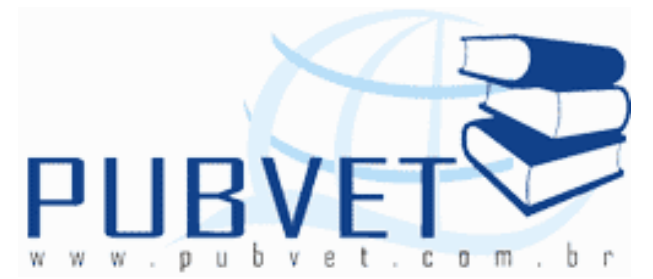

PUBVET, Publicações em Medicina Veterinária e Zootecnia.

\title{
Artrite encefalite caprina
}

\author{
Alexandre de Oliveira Bezerra ${ }^{1}$, Renan Zappavigna Costa Starling ${ }^{1}$, Igor Luiz \\ Salardani Senhorello ${ }^{1}$, Peter Gabriel Ferreira ${ }^{1}$, Renata Côgo Clipes $^{2}$ e Dirlei \\ Molinari Donatele ${ }^{1}$
}

1 Universidade Federal do Espírito Santo, Departamento de Medicina Veterinária; Alegre; Espírito Santo; Brasil.

${ }^{2}$ Instituto Federal do Espírito Santo; IFES-Campus Alegre; Espírito Santo; Brasil.

\section{Resumo}

A artrite encefalite caprina (CAE) é uma síndrome degenerativa progressiva lenta, multissistêmica, provocada pelo Retrovírus Tipo C da subfamília Lentivirinae, afetando os sistemas articular, mamário e nervoso, acarretando grandes prejuízos econômicos, pela morte ou descarte de animais, pela queda na produção, perda de peso, predisposição a infecções secundárias, e gastas com tratamentos e assistência de médicos veterinários. Os sinais clínicos mais frequentes são artrite, mastite e encefalites, apesar de muitos dos animais infectados permaneçam assintomáticos. A forma mais importante de transmissão é a transmissão vertical, por meio da ingestão de leite ou colostro infectado, contudo a transmissão horizontal também pode ocorrer. O controle da CAE consiste na tentativa de diminuir a infecção viral no rebanho. Tendo os cabritos separados das mães ao nascer, devendo ser alimentados com colostro pasteurizado. A CAE consta na lista de doenças de notificação obrigatória da 
BeZerRA, A.O. et al. Artrite encefalite caprina. PUBVet, Londrina, V. 8, N. 21, Ed. 270, Art. 1802, Novembro, 2014.

Organização Mundial de Saúde Animal (OIE), ressaltando a importância da identificação da doença na região (OIE, 2011a).

Palavras-chave: sanidade. caprinocultura. produtividade.

\title{
Caprine arthritis encephalitis
}

\begin{abstract}
The caprine arthritis encephalitis (CAE) is a slow, progressive multisystem degenerative syndrome caused by type $C$ retrovirus subfamily Lentivirinae affecting articular systems, breast and nervous, causing major economic losses, by death or culling of animals, the fall in production, loss weight, predisposition to secondary infections, and spent on treatment and care of veterinarians. The most common clinical signs are arthritis, encephalitis and mastitis, although many of the infected animals remain asymptomatic. The most important way of transmission is vertical transmission through the ingestion of infected colostrum or milk, but horizontal transmission may also occur. The control of CAE is to try to reduce the viral infection in the flock. Having separate mothers at birth goats should be fed pasteurized colostrum. CAE in the list of notifiable by the World Organization for Animal Health (OIE), underscoring the importance of identifying the disease in the region (OIE, 2011a).
\end{abstract}

Keywords: health. goat breeding. productivity.

\section{INTRODUÇÃO}

A artrite encefalite caprina é uma síndrome degenerativa progressiva lenta, multissistêmica, afetando principalmente os sistemas nervoso, articular e mamário, acarretando grandes prejuízos, pela perda dos animais (morte ou descarte), pela diminuição da produção (ROSA, 1996), perda de peso e predisposição a infecção por parasitas gastrointestinais, principalmente nas épocas de chuvas, e gastos com tratamentos devido a maior suscetibilidade a 
BeZerRA, A.O. et al. Artrite encefalite caprina. PUBVet, Londrina, V. 8, N. 21, Ed. 270, Art. 1802, Novembro, 2014.

outras enfermidades (PAULA et al., 2008).

O manejo sanitário inadequado ou ausente favorece a ocorrência de doenças infecciosas, tornando fundamental identificar as principais doenças que acometem essas criações, os fatores de risco e medidas que podem ser tomadas para evitar a disseminação do agente causador da enfermidade (ALBUQUERQUE, 2008). A CAE consta na lista de doenças de notificação obrigatória da Organização Mundial de Saúde Animal (OIE), ressaltando a importância da identificação, do estudo e do controle da doença na caprinocultura regional, nacional e mundial.

\section{DESENVOLVIMENTO}

\section{Etiologia}

O vírus da artrite encefalite caprina (CAEV) é um retrovírus pertencente à subfamília Orthoretrovirinae e ao gênero lentivirus, que também inclui vários outros vírus de grande importância veterinária e humana, como o vírus da imunodeficiência humana (HIV) (ROSA, 1996), ver Quadro 1. Esses são RNA vírus, necessitando para sua replicação de uma transcriptase reversa, produzindo um DNA intermediário denominado DNA proviral (DONOVAN, 2003). São vírus de formato esférico, com cerca de 80 - 100 nM de diâmetro, possuindo a camada mais externa, o envelope, derivado da célula do hospedeiro e em sua superfície projeções de glicoproteínas (MACLACHLAN; DUBOVI, 2011).

Por serem envelopados, esses vírus, são relativamente de fácil inativação por solventes ou detergentes lipídicos, aquecimento (MACLACHLAN; DUBOVI, 2011), periodato, fenol, tripsina, ribonuclease, formaldeído e pH abaixo de 4,2 (DONOVAN, 2003). Porém são mais resistentes, quando comparados com outros vírus, a radiação ultravioleta e radiação- $X$, isso porque o seu genoma diploide pode compensar as mutações, induzidas pela radiação, na replicação viral, durante a transcrição reversa (MACLACHLAN; DUBOVI, 2011). 
BeZerRA, A.O. et al. Artrite encefalite caprina. PUBVet, Londrina, V. 8, N. 21, Ed. 270, Art. 1802, Novembro, 2014.

Quadro 1. Principais doenças causadas por Lentivírus, afetando uma variedade de espécies.

\begin{tabular}{|ll|}
\hline \multicolumn{1}{|c|}{ Espécie acometida } & \multicolumn{1}{c|}{ Doença causada } \\
\hline Ovinos & Maedi-Visna (MV) \\
\hline Caprinos & Artrite Encefalite Caprina (CAE) \\
\hline Equinos & Anemia Infecciosa Equina (AIE) \\
\hline Bovinos & Imunodeficiência Bovina (BIV) \\
\hline Felinos & Imunodeficiência felina (FIV) \\
\hline Primatas não humanos & Imunodeficiência Símia (SIV) \\
\hline Humanos & Imunodeficiência humana (HIV - $1 \mathrm{e}-2$ ) \\
\hline
\end{tabular}

Fonte: Adaptado de Maclachlan e Dubovi, 2011.

O genoma viral é composto por duas fitas lineares simples de RNA idênticas, contendo três genes principais - gag, pol e env -, cada um codificando duas ou mais proteínas importantes para sua replicação. O gene gag codifica três proteínas do núcleo viral, são elas: cápsideo (CA), nucleocápsideo (NC) e da matriz (MA); o gene pol codifica as enzimas transcriptase reversa (RT) e integrasse (IN); e o gene env codifica as proteínas do envelope, superfície (SU) e transmembrana (TM) (MACLACHLAN; DUBOVI, 2011). A replicação viral é regulada por genes virais não estruturais e por fatores ativos produzidos pelas células hospedeiras (NARAYAN; CLEMENTS, 1989).

Além dos genes citados (gag, pol e env), existem outros genes acessórios com função reguladora das diversas etapas da replicação viral. Entre esses genes reguladores existem o tat, que codifica uma proteína que aumenta a eficiência da transcrição pela RNA polimerase, o gene rev, codificando uma proteína que facilita a exportação de determinados RNA mensageiros virais do núcleo para o citoplasma, onde serão traduzidos, o gene nef, regula negativamente a expressão de receptores das células afetadas, tais como o CD4, podendo alterar o estado de ativação das células alvo e o gene 
BeZerRA, A.O. et al. Artrite encefalite caprina. PUBVet, Londrina, V. 8, N. 21, Ed. 270, Art. 1802, Novembro, 2014.

vif, que aumenta a replicação do vírus em linfócitos (MACLACHLAN; DUBOVI, 2011).

\section{Epidemiologia}

A CAE apresenta uma distribuição mundial, sendo relatada e notificada sua ocorrência em vários países (OIE, 2012b). Um estudo epidemiológico utilizando amostras de soro de 14 países, 112 localizações, totalizando 3.729 amostras, apresentou uma prevalência de 33,9\% de animais soropositivos comprovando a distribuição cosmopolita da artrite encefalite caprina (ADAMS et al., 1984). A doença também é amplamente distribuída no Brasil, sendo relatada em vários Estados do país (Quadro 2), e a maioria dos estudos mostra que a doença afeta principalmente rebanhos leiteiros de alta produção, devido a aglomeração de animais, facilitando a transmissão da doença, e, associado a isso, não implantação de medidas sanitárias adequadas (PINHEIRO et al., 2004; SILVA et al., 2005; SOBRINHO et al., 2010). O primeiro isolamento e identificação do vírus da CAE no Brasil foi relatado em 1993 por Hotzell e colaboradores, e ocorreu no Estado do Rio Grande do Sul.

Bandeira et al. (2009), encontraram a CAE distribuída em vários municípios paraibanos, sendo que, dos 15 municípios estudados, 13 possuíam pelo menos um animal soropositivo. Apesar disso, o Estado da Paraíba como um todo, possui uma baixa prevalência, apenas $8,2 \%(42 / 600)$ de animais soropositivos. No estudo, Bandeira et al. (2009), notaram uma maior ocorrência da infecção em machos, justificando este achado pela grande rotatividade de machos reprodutores nos rebanhos, adquiridos muitas vezes de áreas do Brasil com elevada prevalência para CAEV, pois, de acordo com Lara et al. (2005), o vírus da CAE afeta caprinos de qualquer faixa etária, independente do sexo, raça ou produção. 
BeZerRA, A.O. et al. Artrite encefalite caprina. PUBVet, Londrina, V. 8, N. 21, Ed. 270, Art. 1802, Novembro, 2014.

Quadro 2. Prevalências da Artrite Encefalite Carpina em alguns Estados Brasileiros.

\begin{tabular}{|lccc|}
\hline \multicolumn{1}{|c}{ Estado } & $\begin{array}{c}\mathbf{N}^{\circ} \text { de } \\
\text { amostras }\end{array}$ & $\begin{array}{c}\text { Prevalência } \\
\mathbf{( \% )}\end{array}$ & Autores \\
\hline Paraíba & 600 & $8,2 \%$ & Bandeira et al., 2009 \\
\hline Tocantins & 843 & $2,7 \%$ & Sobrinho et al., 2010 \\
\hline Pernambuco & 672 & $3,8 \%$ & Oliveira et al., 2006 \\
\hline Ceará & 4019 & $9,2 \%$ & Pinheiro et al., 2004 \\
\hline São Paulo & 1030 & $43,01 \%$ & Leite et al., 2004 \\
\hline São Paulo & 275 & $34,93 \%$ & Madureira e Gomes, \\
\hline Santa Catarina & 253 & $6,72 \%$ & Sell, 2007 \\
\hline Bahia & 1605 & $13,4 \%$ & Almeida et al., 2001 \\
\hline $\begin{array}{l}\text { Rio Grande do } \\
\text { Norte }\end{array}$ & 42 & $57,21 \%$ & Silva et al., 2005 \\
\hline
\end{tabular}

No Estado do Tocantins também foi observada uma baixa soroprevalência, com apenas 2,3\% (23/843) das amostras positivas ao teste IDGA (Imunodifusão em Agar Gel), não encontrando relação com o sexo dos animais afetados (SOBRINHO et al., 2010). Segundo Sobrinho et al. (2010), isso se deve a recente formação do rebanho caprino na região, e a não realização de práticas que aumentem o risco de transmissão da doença, como utilização de mamadeira coletiva e confinamento dos animais.

Em Pernambuco a soroprevalência encontrada foi de 3,8\%, sendo considerada baixa, não observando relação com a faixa etária ou sexo dos animais (OLIVEIRA et al., 2006). No Ceará, após avaliação de 4019 animais, em 130 propriedades, foi encontrada prevalência de $1 \%$, sendo observada maior ocorrência na região metropolitana de Fortaleza. Das 130 propriedades, $12(9,2 \%)$ apresentaram animais infectados pelo CAEV e notou-se que $100 \%$ das propriedades que possuíam um manejo intensivo da criação foram 
BeZerRA, A.O. et al. Artrite encefalite caprina. PUBVet, Londrina, V. 8, N. 21, Ed. 270, Art. 1802, Novembro, 2014.

positivas para CAE (PINHEIRO et al., 2004).

Observou-se que a doença esta amplamente disseminada nas diversas microrregiões da Bahia, o Estado apresenta prevalência de 13,4\%, notando uma maior ocorrência em fêmeas $(90,23 \%)$ e animais adultos $(89,77 \%)$ (ALMEIDA et al., 2001). No Rio Grande do Norte foram avaliados 11 municípios, sendo encontrada em todos eles a ocorrência da $\mathrm{CAE}$, com uma prevalência média de $11 \% \pm 1,5 \%$. No estudo, foi possível relacionar a maior tecnificação das criações com uma pior qualidade sanitária do rebanho. Os fatores de risco encontrados foram: compra de animais para reposição ou ampliação do rebanho feita sem exigências sanitárias; sala de ordenha, aglomeração dos animais; locais fechados na ocasião do parto; cabras de alta produção, mais susceptíveis a infecção (SILVA et al., 2005).

Em São Paulo foi encontrado uma prevalência de $43,01 \%$ e 34 , 93\% nos anos 2004 e 2007, respectivamente (LEITE et al., 2004; MADUREIRA; GOMES, 2007). Segundo Madureira e Gomes (2007), a alta prevalência no estado é devido a continua aquisição de animais sem avaliação dos critérios sanitários, não havendo relação com o tipo racial afetado, sendo todos os caprinos susceptíveis a ocorrência da CAE.

\section{Transmissão}

O conhecimento do ciclo de vida de um determinado agente infeccioso é fundamental para estabelecer medidas de prevenção e controle de determinada doença. Devendo-se conhecer os seguintes fatores: modo de transmissão, manutenção da infecção e fatores predisponentes para ocorrência da infecção (THRUSFIELD, 2004). O surgimento de novas doenças tem sido relacionado a alguns fatores, como: aumento do transito de animais e pessoas; alterações no meio ambiente/ transformações tecnológicas; doença acometendo mais que uma espécie; e ausência de planos sanitários de controle (BROWN, 2001).

A quantidade de vírus da CAE presente na corrente sanguínea e secreções pode ser baixa, isso é devido ao estado de latência ou baixa 
BeZERRA, A.O. et al. Artrite encefalite caprina. PUBVet, Londrina, V. 8, N. 21, Ed. 270, Art. 1802, Novembro, 2014.

replicação viral após infecção da célula. As possíveis vias de transmissão da CAE ainda não estão completamente elucidadas, porem é sabido que a transmissão da CAE pode ocorrer via vertical ou horizontal (BLACKLAWS et al., 2004).

Transmissão vertical é quando ocorre de uma geração para outra, pela infecção do embrião ou do feto intrauterino, sendo considerada por alguns autores a transmissão através da ingestão de leite/ colostro, também via vertical (THRUSFIELD, 2004). Não é possível descartar a possibilidade de ocorrer transmissão via intrauterina ou durante o parto, uma vez que tem sido identificada a presença do agente viral nas células epiteliais do útero in vivo, reforçando a possibilidade de transmissão por essa via (AHMAD, 2012b), porém isso ainda é controversa, pois apesar de ter sido identificado o DNA proviral do vírus da CAE no trato genital feminino, todos os embriões foram negativos no teste, independente da fertilização ter resultado de monta natural com machos infectados ou inseminação artificial com sêmen infectado (AHMAD et al., 2012a).

A transmissão horizontal é aquela que ocorre de um animal para outro por contato direto ou indireto (vetores) (THRUSFIELD, 2004). Segundo Belknap (2004), para ocorrer à transmissão horizontal é preciso um longo período de contato com secreções de animais doentes. Foi observado que rebanhos caprinos que mantiveram contato com ovinos apresentaram maior soro-conversão (GHANEM et al., 2009), podendo atribuir este fato a grande semelhança antigênica entre os lentivírus de pequenos ruminantes (FEITOSA et al., 2010).

A falta de fiscalização na comercialização e trânsito de animais vivos entre fronteiras nacionais pode ser considerada importante fator contribuinte para a transmissão da doença (GHANEM et al., 2009). O contato direto entre animais é uma importante forma de transmissão do vírus, podendo ocorrer por meio da ingestão de leite/ colostro infectado, via oronasal e via venérea (LARA et al., 2003; BLACKLAWS et al., 2004), por meio das secreções do sistema respiratório, urogenital, glândula mamaria, fezes e saliva (ROSA, 1996), estes 
BeZERRA, A.O. et al. Artrite encefalite caprina. PUBVet, Londrina, V. 8, N. 21, Ed. 270, Art. 1802, Novembro, 2014.

fluidos apresentando geralmente grandes quantidades de macrófagos infectados (REILLY et al., 2004). A transmissão por meio da mamada do leite/ colostro de cabras infectadas é considerada a principal via de transmissão da CAE (RAVAZZOLO; COSTA, 2007), apesar da presença de imunoglobulinas no colostro, esses não conferem proteção contra a infecção do vírus da $\mathrm{CAE}$ (REILLY et al., 2004). A presença de grande quantidade de acido sialico na superfície viral fornece proteção contra a digestão por proteases, favorecendo a infecção via intestinal (HUSO et al., 1988).

A presença do vírus no leite é de grande importância para a saúde publica, tendo se verificado produção de anticorpos anti-CAE em crianças que ingeriram leite de cabras infectadas, porém, ainda não se sabe se essa é apenas uma resposta inespecífica as proteínas virais ou se ocorreu replicação viral nesses indivíduos (CRUZ et al., 2009).

Segundo Guedes et al. (2001) a via aérea é uma possível rota para infecção viral, principalmente quando existe contato intimo e prolongado entre os animais, como é o caso de criações intensivas, sendo o grande número de animais no plantel considerado fator de risco para transmissão horizontal da doença, devido ao maior contato entre os animais e ausência de condições sanitárias adequadas (GHANEM et al., 2009). Geralmente os animais mais velhos são os mais acometidos, isso provavelmente devido à lenta soroconversão após infecção viral, demonstrando a importância da identificação do agente viral no rebanho, podendo ocorrer animais soronegativos, porém portadores do vírus, tornando esses animais importantes fontes de manutenção da doença no rebanho (BOHLAND; D'ANGELINO, 2005).

Peterson et al. (2008), pesquisaram, utilizando PCR, a presença do DNA proviral em ejaculado de caprinos machos, sorologicamente positivos para CAE, comprovando a eliminação do DNA proviral no ejaculado, sugerindo, por não detectar a presença do agente em todos os ejaculados, um efeito sazonal na eliminação do vírus, relacionando a eliminação do vírus com a presença de células da linhagem dos macrófagos no ejaculado, pois essas são as células alvo do vírus, existindo uma relação positiva entre a presença do vírus no 
BeZerRA, A.O. et al. Artrite encefalite caprina. PUBVet, Londrina, V. 8, N. 21, Ed. 270, Art. 1802, Novembro, 2014.

sêmen e o número de leucócitos (PETERSON et al., 2008; AHMAD et al., 2012a), ocorrendo maior eliminação do vírus em caso de lesão testicular, momento em que as células de defesa estão em maior quantidade no ejaculado (ANDRIOLI et al., 2006).

A CAE tem potencial para ser transmitida via acasalamento ou inseminação artificial (I.A.) com sêmen infectado, pois, utilizando PCR, foi detectado o DNA proviral no trato genital feminino (útero e cornos uterinos) sete dias após monta ou I.A., mas ainda não é possível afirmar que essa via de transmissão resulte em novas infecções (AHMAD et al., 2012a). Embora o DNA proviral do vírus da CAE tenha sido identificado no trato genital feminino, todos os embriões foram negativos no teste, independente da fertilização ter resultado de monta natural com machos infectados ou inseminação artificial com sêmen infectado in vitro (AHMAD et al., 2012b), demonstrando a importância da presença da Zona Pelúcida intacta envolvendo o embrião, fornecendo proteção mecânica e fisiológica contra a infecção da célula embrionária (REICHENBACH et al., 2008).

A transmissão indireta pode ocorrer através de transferência de embrião, inseminação artificial, via ambiental e iatrogênica (BLACKLAWS et al., 2004). A via iatrogênica, ou seja, por meio da ordenhadeira mecânica (BLACKLAWS et al., 2004), de agulhas, tatuadores e outros materiais contaminados com sangue de animais infectados, é considerada a segunda principal via de transmissão do vírus (LARA et al., 2003; RAVAZZOLO; COSTA, 2007). Não existem evidencias de transmissão por picada de insetos (REILLY et al., 2004)

\section{Patogenia}

A infecção natural por Lentivírus de pequenos ruminantes geralmente ocorre através de superfícies mucosas, mais frequentemente trato respiratório e intestinal (Figura 1) (BLACKLAWS, 2012). Após penetração do vírus nas células alvo, monócitos, macrófagos e células dendriticas, o vírus, que é RNA fita simples, produz o DNA proviral utilizando uma enzima denominada transcriptase reversa, após isso o DNA é integrado ao genoma do hospedeiro, 
BeZerRA, A.O. et al. Artrite encefalite caprina. PUBVet, Londrina, V. 8, N. 21, Ed. 270, Art. 1802, Novembro, 2014.

causando uma infecção persistente (REILLY et al., 2004).

As células alvo infectadas, presentes na mucosa, migram para os linfonodos regionais causando infecção dos macrófagos, que, por sua vez, atinge os vários tecidos (BLACKLAWS, 2012), como do pulmão, do líquido sinovial, do sistema nervoso central e da glândula mamaria, que são os principais acometidos. Assim que o monócito chega ao tecido e se transforma em macrófago, o vírus se prolifera rapidamente, induzindo uma vigorosa resposta imune, responsável pelos sinais de inflamação. Os macrófagos, ao serem infectados, produzem um uma proteína viral semelhante as do complexo de histocompatibilidade principal $(\mathrm{MHC})$, que, por sua vez, estimula a produção de citocinas pelos linfócitos $T$, o macrófago infectado também fica mais suscetível a sofrer ativação, induzindo a proliferação de linfócitos e macrófagos. (REILLY et al., 2004).

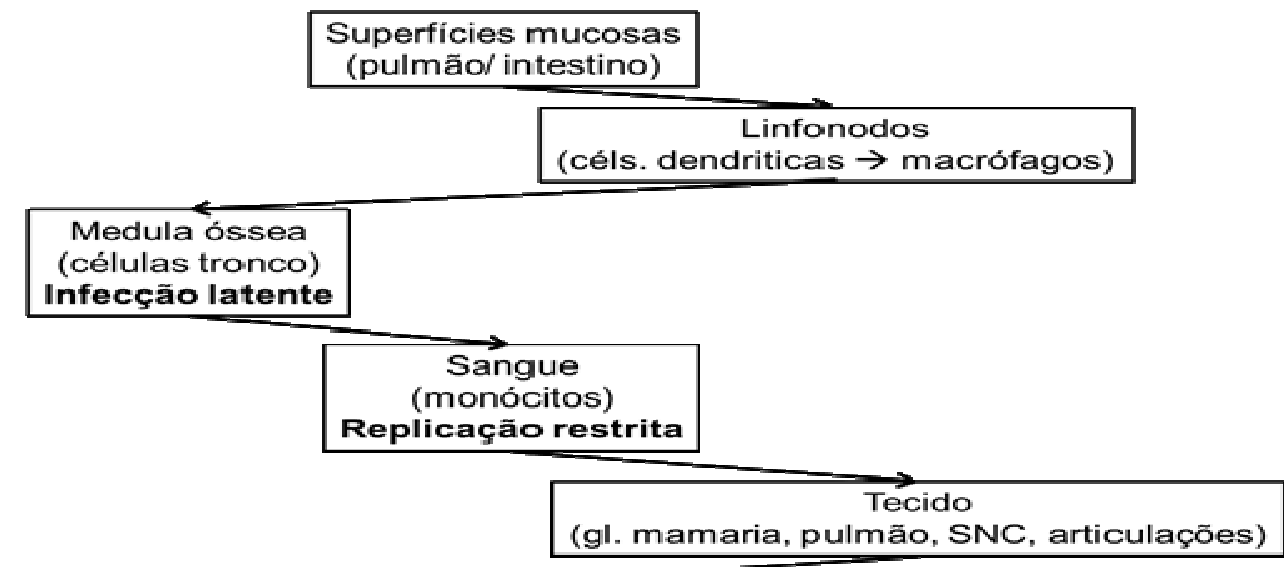

Macrófagos e Células dendriticas

(Replicação viral)

Ativação do Sistema Im une contra os antígenos virais

Infiltrado inflamatório

(Linfócitos/ macrófagos/ células plasmáticas)

Figura 1. Patogênese das infecções causadas por Lentivírus de pequenos ruminantes. Fonte: Adaptado de Blacklaws (2012). 
BeZERRA, A.O. et al. Artrite encefalite caprina. PUBVet, Londrina, V. 8, N. 21, Ed. 270, Art. 1802, Novembro, 2014.

A persistente da infecção é devida: à latência, nos monócitos, pelo DNA proviral; a replicação viral só ocorrer após a migração do monócito para o tecido, onde se transforma em macrófago; baixa concentração de anticorpos neutralizantes anti-CAE, incapaz de eliminar o vírus; a ocorrência constante de mutações, criando muitas variantes antigênicas, dificultando ação do sistema imune (REILLY et al., 2004); possivelmente o DNA proviral se integre ao genoma de células tronco da medula óssea, acarretando continua produção de células infectadas ao longo da vida do animal (BLACKLAWS, 2012).

Macrófagos infectados produzem fatores quimiotáticos no tecido inflamado recrutando novas células ao tecido afetado, geralmente cérebro, medula espinhal, pulmão, glândula mamária e sinóvia, aumentando a carga viral nestes órgãos (ZINK et al., 1990). Observações mais recentes sugerem que a infecção viral aumente a expressão de citocinas, como, interleucina-16, interleucina-8 e MCP-1 (Proteína Quimiotática de Monócito - 1), e as propriedades quimiotáticas destas podem contribuir para exacerbação das lesões inflamatórias desta doença, por aumentar a infiltração de monócitos, macrófagos e linfócitos nos locais de replicação viral (LECHNER et al., 1997; NIMMANAPALLI et al., 2010).

Segundo Murphy et al. (2010), o tropismo do CAE por determinado tecido e a patogênese da doença ainda permanecem indeterminados, sugerindo várias hipóteses, sendo elas: (1) a região do envelope (env) e dos receptores virais é a menos conservada do genoma viral. A variabilidade na sequência de nucleotídeos dentro do gene env pode, portanto, afetar o tropismo pelo tecido, quer direta ou indiretamente; (2) outros cofatores, ainda indefinidos, podem agir sinergicamente com o vírus e influenciar no tropismo; (3) os fatores do hospedeiro podem determinar ou afetar o tropismo tecidual (isto é, o complexo de histocompatibilidade principal I ou II); ou (4) o tropismo do vírus CAE talvez possa culminar de eventos aleatórios que ocorram no início da infecção.

Apesar de nos órgãos alvo ser observado uma quantidade muito maior de células infectadas pelo vírus da $C A E$, foi observado à presença de proteínas 
BeZerRA, A.O. et al. Artrite encefalite caprina. PUBVet, Londrina, V. 8, N. 21, Ed. 270, Art. 1802, Novembro, 2014.

virais em outras células de tecidos que não apresentavam inflamação, podendo representar reservatórios do vírus. Algumas dessas células não eram macrófagos, por exemplo, células epiteliais das criptas intestinais, dos túbulos renais, dos folículos ovarianos e da tireoide. Essas células podem ser infectadas por fusão aleatória quando o macrófago infectado passa através do tecido epitelial, sugerindo que o tropismo do vírus possa se estender além dos macrófagos, podendo ocorrer replicação viral em uma variedade de células (ZINK et al., 1990; BLACKLAWS, 2012).

O vírus da CAE pode comprometer o sistema imune do animal, favorecendo a ocorrência de infecções secundarias bacterianas e parasitárias (ZINK et al., 1990). A existência de grande quantidade de ácido sialico na superfície da partícula viral é importante, pois diminui a antigenicidade da partícula e protege-a contra a neutralização dos poucos anticorpos formados, contribuindo na patogenia e persistência da doença, pois possibilita "fuga" contra a resposta imune do animal. Portanto, torna-se ainda mais complexa a pesquisa por vacinas contra esta enfermidade, já que a resposta imune humoral pouco interfere na replicação viral (HUSO et al., 1988). A titulação de anticorpos teve correlação positiva com a gravidade das lesões inflamatórias articulares, ou seja, a resposta imune pode contribuir para patogenia da doença, indicando ser um processo imunopatológico mediado por imunocomplexos (KNOWLES JUNIOR et al., 1990; FLORES, 2007).

\section{Sinais Clínicos}

A maioria dos animais infectados permanecem assintomáticos (REILLY et al., 2004), a forma clinica geralmente se manifesta em rebanhos com alta prevalência de animais soropositivos (RAZZOLO; COSTA, 2007).

Os sinais clínicos podem ser primários ou secundários. Os sinais clínicos primários, de ocorrência mais comum, são causados diretamente pela ação viral no tecido, ou seja, devido à resposta imune gerada pela replicação viral. Enquanto que os sinais clínicos secundários são decorrentes da ação imunossupressora do vírus, levando a ocorrência de infecções oportunistas 
BeZerRA, A.O. et al. Artrite encefalite caprina. PUBVet, Londrina, V. 8, N. 21, Ed. 270, Art. 1802, Novembro, 2014.

(NARAYAN; CLEMENTS, 1989).

O sinal clínico mais comum da doença é a artrite, acometendo geralmente animais mais velhos, entre dois a nove anos de idade, caracterizada pelo aumento de volume circular da articulação, sendo a articulação do carpo, de um ou ambos os membros anteriores, a mais acometida. Ocorre inflamação com espessamento da capsula articular, deposição de minerais e edema do tecido conjuntivo periarticular, como consequência, os sinais são dificuldade de locomoção e claudicação (REILLY et al., 2004). O índice clínico, antigamente utilizado para o diagnóstico desta enfermidade era o cálculo baseado na diferença entre o diâmetro do osso metacarpo e da articulação carpo-metacarpiana, não sendo mais utilizado por não ser um método confiável (MOREIRA et al., 2007).

Outra forma clínica, porém menos comum, afeta principalmente animais jovens entre um a quatro meses de idade, é a neurológica, caracterizada por leucoencefalomielite. Os sinais clínicos mais comuns são paresia que evolui para tetraparesia, ataxia secundaria dos posteriores, andar em circulo, cegueira, nistagmo, tremores e inclinação da cabeça (MACHEN et al., 2004).

O sistema respiratório pode ser acometido, sendo caracterizado por pneumonia intersticial crônica, lesões encontradas principalmente nos lobos caudal ou crânio ventral do pulmão (BELKNAP, 2004), levando aos sinais clínicos de aumento da frequência respiratória, intolerância ao exercício, dispneia e tosse seca (REILLY et al., 2004).

\section{Diagnóstico}

De acordo com a Organização Mundial de Saúde Animal (OIE, 2012 a), a CAE é uma enfermidade de notificação obrigatória ao serviço oficial da região, no caso o Ministério da Agricultura, Pecuária e abastecimento (MAPA) e a Secretaria de Agricultura do Município (BRASIL, 2004).

Para diagnóstico das lentivíroses, os testes sorológicos podem ser realizados apenas em animais com mais de seis meses de idade, tendo validade de até três meses (BRASIL, 2004), pode ser rotineiramente realizado, 
BeZERRA, A.O. et al. Artrite encefalite caprina. PUBVet, Londrina, V. 8, N. 21, Ed. 270, Art. 1802, Novembro, 2014.

como por exemplo, o teste de imunodifusão em gel de Agar (IDGA) (BRASIL, 2004), ELISA (ANDRÉS et al., 2005), Western blot (OLIVEIRA et al., 2008) e Dot blot (PINHEIRO et al., 2006). O PCR (Reação em Cadeia da Polimerase) pode ser uma importante ferramenta para detecção da presença do material genético do vírus, devendo ser utilizado em associação com os testes sorológicos (PETERSON et al., 2008).

Outras possibilidades de diagnóstico, porém com pouca utilização prática, são o isolamento viral, a imuno-histoquímica (REINA et al., 2009) e a histopatologia dos órgão acometidos (BELKNAP, 2004). O teste aceito como padrão pela Organização Mundial de Saúde animal (OIE) são o IDGA e ELISA (OIE, 2011c), devendo ser realizados por laboratórios credenciados ao Ministério da Agricultura, Pecuária e abastecimento (MAPA) (BRASIL, 2004).

Apesar da alta sensibilidade e especificidade dos testes sorológicos para detecção dos anticorpos anti-CAEV, a lenta soroconversão não permite uma associação entre a infeç̧ão com o momento da produção de anticorpos contra o vírus, ou seja, podem existir animais soronegativos, porém infectados com o vírus, apenas ainda não apresentaram resposta imune humoral. Portanto, o PCR pode ser útil para comprovar a real existência do RNA proviral no sangue, sêmen e outros tecidos (PETERSON et al., 2008), sendo importante, para um programa eficiente de controle e erradicação da doença, associar os testes sorológicos com o PCR (BRINKHOF et al., 2010).

O ELISA possui maior especificidade e sensibilidade, quando comparado com o IDGA, para detectar animais infectados (ROSATI et al., 1995). Alguns estudos mostram que a associação entre ELISA e PCR pode proporcionar ótimos resultados na deteç̧ão dos animais infectados (ANDRÉS et al., 2005). Segundo Plaza et al. (2009), amostras de soro de leite podem ser utilizadas para diagnóstico de CAE através do método ELISA, sendo esse um método de baixo custo quanto comparado aos métodos tradicionais, além de ser um teste não invasivo e simplificado, podendo ser usado para o diagnóstico de rotina no rebanho. Isso possibilita realizar um acompanhamento epidemiológico do rebanho mais efetivo, podendo ser utilizada amostras individuais ou do tanque 
BeZerRA, A.O. et al. Artrite encefalite caprina. PUBVet, Londrina, V. 8, N. 21, Ed. 270, Art. 1802, Novembro, 2014.

de expansão.

O teste western blot possui potencial para ser utilizado no diagnóstico das lentiviroses, necessitando, porém de maiores estudos para padronização da técnica (OLIVEIRA et al., 2008). Uma alternativa para detecção de anticorpos anti-CAEV é o teste dot-blot, tendo como vantagem o menor custo e maior praticidade, podendo ser realizado na própria propriedade ou em eventos agropecuários, além de ter apresentado maior sensibilidade quando comparado com o IDGA (PINHEIRO et al., 2006).

Apesar de todas as possibilidades e formas de diagnóstico, ainda é muito limitado no Brasil o uso dessas técnicas, sendo o método IDGA o único utilizado rotineiramente. Outro fator importante é a inexistência de laboratórios credenciados ao Ministério da Agricultura para controle das lentiviroses de pequenos ruminantes, dificultando o diagnóstico da enfermidade.

\section{Prevenção e Controle}

A implantação de um programa sanitário é fundamental para evitar a introdução e disseminação de agentes infecciosos no rebanho (ALBUQUERQUE, 2008), necessitando-se conhecer quais os fatores de risco importantes para manutenção e disseminação da doença no rebanho (GHANEM et al., 2009). Uma estratégia eficiente deve permitir a diminuição da prevalência, possibilitando obter status de livre da doença (REINA et al., 2009).

No Brasil foi criado, pelo Ministério da Agricultura, Pecuária e Abastecimento, no ano de 2004, o Plano Nacional de Vigilância e Controle de Lentiviroses de Pequenos Ruminantes, que é parte integrante do Programa Nacional de Sanidade de Caprinos e Ovinos, aprovado pela instrução normativa $n^{\circ} 53$ (2004). Este plano estabelece normas para transito de animais, para participação em eventos agropecuários, além de estabelecer medidas para certificação de propriedades livres de CAE (BRASIL, 2004).

A primeira medida a ser adotada em um programa de controle da CAE é determinar a prevalência no rebanho (REINA et al., 2009), devendo, a colheita 
BeZerRA, A.O. et al. Artrite encefalite caprina. PUBVet, Londrina, V. 8, N. 21, Ed. 270, Art. 1802, Novembro, 2014.

de sangue destinada a realização dos testes sorológicos, ser efetuada por médicos veterinários cadastrados ao programa (BRASIL, 2004). Uma das indicações do programa é abate (PLAZA et al., 2009) ou isolamento e restrição da movimentação dos animais positivos, caso a prevalência seja muito alta, evitando perda de grande parte do rebanho (NORD et al., 1998; REINA et al., 2009), portanto, um diagnóstico preciso é fundamental. De acordo com a legislação Brasileira, não é permitido à realização de reteste para os animais considerados positivos (BRASIL, 2004).

A compra e introdução de novos animais no plantel deve respeitar um período de quarentena de até seis meses, devendo, nesse período, serem realizados dois testes para lentiviroses (BRASIL, 2004).

Durante a ordenha, deve-se realizar uma linha de ordenha mantendo a seguinte ordem: ordenhar primeiro as fêmeas jovens negativas; em segundo as fêmeas adultas negativas e, por fim, as fêmeas positivas (BRASIL, 2004).

Para machos doadores de sêmen, o PCR de amostras de sangue é um coadjuvante essencial, utilizado em associação com teste imunológico, para a comprovação da infecção do vírus no animal (PETERSON et al., 2008). Segundo Andrioli (2006), em um programa de controle da CAE, é fundamental a identificação do DNA proviral no sêmen dos reprodutores, considerando o risco da transmissão, tanto por meio da monta natural, como por meio da inseminação artificial.

A lavagem do sêmen, processo usual para criopreservação do sêmen caprino, reduziu significativamente a carga viral do mesmo, porém não foi suficiente para elimina-la, pois o processo de lavagem remove apenas o plasma seminal e não os leucócitos, células alvo do vírus (ANDRIOLI et al., 2006). Porém, Fieni et al. (2012), utilizando sêmen experimentalmente contaminado com o vírus da CAE em fertilizações in vitro (FIV), mostraram claramente que as primeiras quatro lavagens, feitas de acordo com as indicações da Sociedade Internacional de Transferência de Embriões (IETS), foram suficientes para remover partículas do vírus da $C A E$, demonstrando que a presença do vírus durante a FIV não resultou em embriões infectados, sendo 
BeZerRA, A.O. et al. Artrite encefalite caprina. PUBVet, Londrina, V. 8, N. 21, Ed. 270, Art. 1802, Novembro, 2014.

possível produzir embriões livres do vírus da CAE mesmo usando sêmen infectado in vitro. De acordo com Ahmad et al. (2012a), é possível obter embriões livres da CAE independente do status infeccioso do sêmen, mostrando a transferência de embriões como uma excelente ferramenta para controle da enfermidade. O vírus da CAE possui tropismo por células da granulosa, podendo ser uma fonte de infecção para embriões produzidos in vitro por métodos mais recentes, pois, atualmente, esta célula tem sido utilizada para maturação in vitro de oócitos, devendo-se adotar medidas preventivas, como certificação dos animais doadoras das células da granulosa como negativos (LAMARA et al., 2001).

Por fim, a certificação de uma propriedade como livre de lentiviroses é obtida utilizando-se as técnicas de PCR e Western Blot (BRASIL, 2004), o que difere do recomendado como teste padrão pela OIE, PCR e ELISA (OIE, 2012c).

\section{CONSIDERAÇÕES FINAIS}

A Artrite Encefalite Caprina é uma enfermidade disseminada por todo território mundial, inclusive no território brasileiro em criatórios caprino, se tratando de uma doença cosmopolita. Muita das vezes o desconhecimento da enfermidade pelos proprietários, muitos casos se tornam aparentes, por não serem diagnosticados, dificultando assim a erradicação da doença, ocasionando assim perdas econômicas na lucratividade da atividade de criação de caprinos.

Logo em rebanhos com uma alta prevalência, a CAE pode causar diminuição da produção, descarte de animais e aparecimento de doenças secundárias. Não conseguindo assim realizar um programa de sanidade que seja eficiente para o controle e ate mesmo erradicação desta enfermidade de grande importância nos criatórios de caprinos, uma vez que se trata de uma enfermidade de difícil controle, quando não laçamos mãos de medidas adequadas de manejo e sanidade. 


\section{REFERÊNCIAS}

AHMAD, M.Z.A.A.; CHEBLOUNE, Y.; CHATAGNON, G.; PELLERIN, J.L.; FIENI, F. Is caprine arthritis encephalitis virus (CAEV) transmitted vertically to early embryo development stages (morulae or blastocyst) via in vitro infected frozen semen?. Theriogenology, v. 77, n. 8, p. 1673-1678, 2012a.

AHMAD, M.Z.A.A.; DUBREIL, L.; CHATAGNON, G.; KHAYLI, Z.; THERET, M.; MARTIGNAT, L.; CHEBLOUNE, Y.; FIENI, F. Goat uterine epithelial cells are susceptible to infection with Caprine Arthritis Encephalitis Virus (CAEV) in vivo. Veterinary Research, v. 43, n. 5, p. 1 - 7, 2012 b.

ALBUQUERQUE, I.R.R. Perfil sanitário de rebanho caprino da região de Senhor do Bonfim, Bahia - Brasil. 2008. Monografia (Graduação em Medicina Veterinária) - Centro de Saúde e Tecnologia Rural, Universidade Federal de Campina Grande, Patos.

ALMEIDA, M.G.A.R.; ANUNCIAÇÃO, A. V. M.; FIGUEREDO, A.; MARTINEZ, T. C. N. ; LABORDA,S. S. Dados sorológicos sobre a presença e distribuição da artrite-encefalite caprina (CAE) no Estado da Bahia , Brasil. Revista Brasileira de Saúde e Produção Animal, v. 1, n. 3, p.78-83, 2001.

ANDRÉS, D.; KLEIN, D.; WATT, N.J.; BERRIATUA, E.; TORSTEINSDOTTIR, S.; BLACKLAWS, B.A.; HARKISS, G. D. Diagnostic test for small ruminant lentiviruses. Veterinary Microbiology, v. 107, p. 49-62, 2005.

ANDRIOLI, A.; GOUVEIA, A.M.G.; MARTINS, A.S.; PINHEIRO, R.R.; SANTOS, D.O. Fatores de risco na transmissão do lentivírus caprino pelo sêmen. Pesquisa Agropecuária Brasileira, Brasília, v.41, n.8, p.1313 - 1319, 2006.

BANDEIRA, D.A.; CASTRO, R.S.; AZEVEDO, E.O.; MELO, L.S.S.; MELO, C.B. Seroprevalence of caprine arthritis-encephalitis virus in goats in the Cariri region, Paraiba state, Brazil. The Veterinary Journal, v. 180, n. 3, p. 399-401, 2009.

BELKNAP, E.B. Enfermidades do Sistema Respiratório. In: PUGH, D.G. Clínica de ovinos e caprinos. São Paulo: Roca, 2004. p. 119 - 143.

BLACKLAWS, B.A. Small ruminant lentiviruses: Immunopathogenesis of visna-maedi and caprine arthritis and encephalitis virus. Comparative Immunology, Microbiology and Infectious Diseases, v. 35, n. 3, p. 259- 269, 2012.

BOHLAND, E.; D'ANGELINO, J. L. Artrite-Encefalite Caprina: avaliação dos aspectos produtivos e reprodutivos de animais infectados e não infectados. Brazilian Journal Veterinaria Research Animal Science, v.42, n.2, p.81-88, 2005

BRASIL. Portaria n 103, de 7 de dezembro de 2004. Ministério da Agricultura Pecuária e Abastecimento. Disponível em: <http://extranet.agricultura.gov.br/sislegis>. Acesso em: 06 abr. 2012.

BRINKHOF, J.M.A.; MOLL, L.; MAANEN, C. V.; HOUWERS, D.J. Use of serology and polymerase chain reaction for the rapid eradication of small ruminant lentivirus infections from a sheep flock: A case report. Research in Veterinary Science, v. 88, n. 1, p. 41-43, 2010.

BROWN, C. La importância de las enfermidades emergentes para la sanidad animal, la salud pública y el comercio. OIE, 2001. Disponível em:

<ftp://ftp.oie.int/69SG_2001/E_69_SG_9.pdf>. Acesso em: 22 mai 2012. 
CRUZ, E.T.; ROMERO, I.A.F.; SUÁREZ, S.O.; GONZÁLEZ, R.H.; GARCÍA, R.S.; SALGADO, A.V.; MÉNDEZ, V.C.B.; FAVELA, F.B.; SETIÉND, A.A. Frequency of the Serological Reactivity Against the Caprine Arthritis Encephalitis Lentivirus gp135 in Children Who Consume Goat Milk.

Archives of Medical Research, v. 40, n. 3, p. $204-$ 207, 2009.

DONOVAN, M.D. Retroviridae. In: HIRSA, D.C.; ZEE, Y.C. Microbiologia Veterinária. Rio de Janeiro: Guanabara Koogan, 2003. p. $411-428$.

FAO, Food and Agriculture Organizatio (2012). FAOSTAT - FAO Statistics Division/ Production: Livestock Primary. Disponível em: <http://faostat.fao.org/site/569/default.aspx\#ancor>.

Acesso em: 04/05/2012.

FEITOSA, A.L.V.L.; TEIXEIRA, M.F.S.; PINHEIRO, R.R.; CUNHA, R.M.S.; LIMA, J.P.M.S., ANDRIOLI, A.; DANTAS, T.V.M.; MELO, V.S.P.; PINHEIRO, D.C.S.N. Phylogenetic analysis of small ruminant lentiviruses from Northern Brazil. Small Ruminant Research, v. 94, n. 1, p. 205-209, 2010.

FIENIA, F.; PELLERINA, J.L.; ROUXA, C.; POULIN, N.; BARIL, G.; FATET, A.; VALASG, S.; CHATAGNONA, G.; MERMILLOD, P.; GUIGNOTC, F. Can caprine arthritis encephalitis virus (CAEV) be transmitted by in vitro fertilization with experimentally infected sperm?.

Theriogenology, v. 77, n. 3 , p. 644-651, 2012.

FLORES, E.F. Patogenia das Infecções Virais. In: Editora UFSM, 2007. cap. 8, p. $191-234$.

Virologia Veterinária. Santa Maria:

FRANÇA, F.M.C.; HOLANDA JUNIOR, E.V.; SOUZA NETO, J.M. Análise da Viabilidade Financeira e Econômica do Modelo de Exploração de Ovinos e Caprinos No Ceará por Meio do Sistema Agrossilvipastoril. Revista Econômica do Nordeste, Fortaleza, v. 42, n. 2, p. $287-308$, 2011.

GHANEM, Y.M.; EL-KHODERY, S.A.; SAAD, A.A.; ELRAGABY, S.A.; ABDELKADER, A.H.; HEYBE, A. Prevalence and risk factors of caprine arthritis encephalitis virus infection (CAEV) in Northern Somalia. Small Ruminant Research, v. 85, n. 2, p. 142-148, 2009.

GUEDES, M.I.M.C. ; SOUZA, J.C.A.; GOUVEIA, A.M.G. Infecção experimental em cabritos pelo vírus da artrite encefalite. Arquivo Brasileiro de Medicina Veterinária e Zootecnia, v. 53, n.1, Belo Horizonte, p. $15-20,2001$.

HUSO, D.L.; NARAYAN, O.; HART, G.W. Sialic Acids on the Surface of Caprine ArthritisEncephalitis Virus Define the Biological Properties of the Virus. Journal of virology, v. 62, n. 6, p. 1974-1980, 1988.

KNOWLES JUNIOR., D.; CHEEVERS, W.; MCGUIRE, T.; STEM, T.; GORHAM, J. Severity of Arthritis Is Predicted by Antibody Response to gp135 in Chronic Infection with Caprine Arthritis-Encephalitis Virus. Journal of virology, v. 64, n. 5, p. 2396-2398, 1990.

LAMARA A.; FIENI, F.; LAKHAL, L. M.; TAINTURIER, D.; CHEBLOUNE, Y. Efficient replication of caprine arthritis-encephalitis virus in goat granulosa cells. Virus Research, v. 79, n. 5, p. $165-172,2001$.

LARA, M.C.C.S.H.; BIRGEL JUNIOR, E.H.; FERNANDES, M.A.; BIRGEL, E.H. Infecção experimental do vírus da artrite-encefalite dos caprinos em cabritos. Arquivo do Instituto Biológico, São Paulo, v.70, n.1, p.51-54, 2003. 
LARA, M.C.C.S.H.; BIRGEL JUNIOR, E.H.; GREGORY, L.; BIRGEL, E.H. Aspectos clínicos da artrite-encefalite dos caprinos. Arquivo Brasileiro de Medicina Veterinária e Zootecnia, v.57, n.6, p. $736-740,2005$.

LECHNER, F.; MACHADO, J.; BERTONI, G.; SEOW, H.F.; DOBBELAERE, D.A.E.; PETERHANS, E. Caprine Arthritis Encephalitis Virus Dysregulates the Expression of Cytokines in Macrophages.

Journal of virology, v. 71, n. 10, p. 7488-7497, 1997.

LEITE, B.L.S.; MODOLO, J.R.; PADOVANI, C.R.; STACHISSINI, A.V.M.; CASTRO, R.S., SIMÕES, L.B. Avaliação da taxa de ocorrência da artrite-encefalite caprina a vírus pelas regionais do escritório de Defesa Agropecuária do estado de São Paulo, Brasil, e seu mapeamento por meio de Sistema de Informações Geográficas. Arquivo do Instituto Biológico, São Paulo, v.71, n.1, p.21-26, 2004.

MACHEN, M.R.; WALDRIDGE, B.M.; CEBRA, C.; CEBRA, M.; BELKNAP, E.B.; WILLIAMSON, L.H.; PUGH, D.G. Enfermidades do Sistema Nervoso. In: PUGH, D.G. Clínica de ovinos e caprinos. São Paulo: Roca, 2004. p. 311 - 352.

MACLACHLAN, N.J.; DUBOVI, E.J. RETROVIRIDAE. In: 4. ed. Londres: Elsevier, 2011. Cap. 14, p. 243 - 274.

Fenner's Veterinary Virology.

MADUREIRA, K.M.; GOMES, V. Prevalência da artrite encefalite caprina (CAE) em propriedades leiteiras do Estado de São Paulo. Revista de Ciências Veterinárias, v. 5, n. 5, p. 78 - 83, 2007.

MOREIRA, M.C.; OELEMANN,W.M.R.; LILENBAUM, W. Dados sorológicos da artrite-encefalite caprina no estado do Rio de Janeiro (BR) e avaliação do uso do índice clínico como ferramenta de diagnóstico. Revista Brasileira de Medicina Veterinária, v. 29, n, 2, p. 51 - 53, 2007.

MURPHY, B.; MCELLIOTT, V.; VAPNIARSKY, N.; OLIVER, A.; ROWE, J. Tissue tropism and promoter sequence variation in caprine arthritis encephalitis virus infected goats. Virus Research, v. 151, n. 2, p. 177-184, 2010.

NARAYAN, O.; CLEMENTS, J.E. Biology and Pathogenesis of Lentiviruses. Journal of General Virology,v. 70, n. 7, p. 1617-1639, 1989.

NIMMANAPALLI, R.; SHARMILA, C.; REDDY, P.G. Immunomodulation of caprine lentiviral infection by interleukin-16. Comparative Immunology, Microbiology and Infectious Diseases, v. 33, p. $529-536,2010$.

OIE, Animal health in the World: OIE Listed diseases, 2012. Disponível em: <http://www.oie.int/animal-health-in-the-world/oie-listed-diseases-2012/>. Acesso em: 27 abr. 2012 a.

OIE. Disease Timelines: Caprine arthritis/ encephalitis (2005 - 2012). World Animal Health Information Database. Disponível em:

$<$ http://web.oie.int/wahis/public.php?page=disease_timelines\&disease_type=Terrestrial\&disea se_id=46>. Acesso em: 03/05/2012b.

OIE. Prescribed and Alternative Diagnostic Tests for OIE Listed Diseases. Disponível em: $<$ http://www.oie.int/index.php?id=169\&L=0\&htmfile=chapitre_1.1.3.htm>. Acesso em: 08/08/2012c. 
OLIVEIRA, M.M.M.; CASTRO, R.S.; CARNEIRO, K.L.; NASCIMENTO, S.A.; CALLADO, A.K.C. ; ALENCAR, C.S.A.; COSTA, L.S.P. Anticorpos contra lentivírus de pequenos ruminantes em caprinos e ovinos em abatedouros do estado de Pernambuco. Arquivo Brasileiro de Medicina Veterinária e Zootecnia, v.58, v.5, p. 947-949, 2006.

OLIVEIRA, M.M.M. Diagnóstico e controle de Lentivírus de Pequenos Ruminantes (LVPR) em caprinos. 2007. Tese (Doutorado em Ciência Veterinária) - Programa de Pós-Graduação em Ciência Veterinária, Universidade Federal Rural de Pernambuco, Recife.

OLIVEIRA, M.M.M.; MELO, M.A.; ANDRADE, P.P.; GOMES, S.M.; CAMPOS, A.C.; NASCIMENTO, S.A.; CASTRO, R.S. Western blot para o diagnóstico das infecções pelos lentivírus de pequenos ruminantes em caprinos: um método simples para a produção de antígeno. Arquivo do Instituto Biológico, São Paulo, v.75, n.3, p.263-270, 2008.

PAULA, N.R.O.; ANDRIOLI, A.; CARDOS, J.F.S.; SOUZA, F.M.L.; SOUZA, K.C.; PINHEIRO, R.R.; ALVES, F.S.F.; TEIXEIRA, M.F.S. Parâmetros clínicos e hematológicos de reprodutores caprinos infectados naturalmente pelo vírus da artrite encefalite caprina durante a transição da estação seca para chuvosa no ceará. Arquivo Instituto Biológico, v. 75, n. 2, p. 141 - 147, 2008.

PETERSON, K.; BRINKHOF, J.; HOUWERS, D.J.; COLENBRANDER, B.; GADELLA, B.M. Presence of pro-lentiviral DNA in male sexual organs and ejaculates of small ruminants.

Theriogenology, v. 69, n. 4 , p. 433-442, 2008.

PINHEIRO, R.R.; GOUVEIA, A.M.G.; ALVES, F.S.F.; ANDRIOLI, A. Perfil de propriedades no estado do Ceará relacionado à presença do lentivírus caprino. Ciência Animal, v. 14, n. 1, p. 29-37, 2004.

PINHEIRO, R.R.; OLORTEGUI, C.D.C.; GOUVEIA, A.M.G.; ARAUJO, S.C., ANDRIOLI, A. Desenvolvimento de dot-blot para detecção de anticorpos para o vírus da Artrite Encefalite Caprina em caprinos. Revista Portuguesa de Ciências Veterinárias, v. 101, p. 51-56, 2006

PLAZA, M.; SÁNCHEZ, A.; CORRALES, J.C.; FE, C. D.; CONTRERAS, A. Caprine arthritis encephalitis virus diagnosed by ELISA in lactating goats using milk samples. Small Ruminant Research, v. 81, n. 2 - 3, p. $189-192,2009$.

RAVAZZOLO, A.P.; COSTA, U. Retroviridae. In: FLORES, E. F. Virologia Veterinária. Santa Maria: UFSM, 2007. p. 809-830

REICHENBACH, H.D.; OLIVEIRA, M.A.L.; LIMA, P.F.; ANDRADE, J.C.O.; TENÓRIO FILHO, F; SANTOS, M.H.B.; OLIVEIRA FILHO, B.D.; MEIRINHOS, M.L.G.; SANTOS FILHO, A.S.S. Transferência e Criopreservação de Embriões Bovinos. In: GONÇALVES, P.B.D; FIGUEIREDO, J.R.; FREITAS, V.J.F. Biotécnicas Aplicadas à Reprodução Animal. 2. ed. São Paulo: Rocoa, 2008. p. $201-239$.

REILLY, L.K.; BAIRD, A.N.; PUGH, D.G. Enfermidades do Sistema Musculoesquelético. In: PUGH, D.G. Clínica de ovinos e caprinos. São Paulo: Roca, 2004. p. $251-286$.

REINA, R.; BERRIATUA, E.; LUJÁN L.; JUSTE, R.; SÁNCHEZ, A.; ANDRÉS, D.; AMORENA, B. Prevention strategies against small ruminant lentiviruses: An update. The Veterinary Journal, v. 182, n. 1, 2009, p. 31-37.

ROCHA, L.P.; FRAGA, A.B.; ARAÚJO,A.J.T.; FIGUEIRA, B.R.F.; PACHECO, K.M.G.; SILVA, A.F.L.; RODRIGUES, B.E.D.S. Desempenho de Cordeiros Cruzados Em Alagoas, Brasil. Archivos de Zootecnia, v. 58, n. 221, p. $145-148,2009$. 
ROSA, J.S. Enfermidades em caprinos: diagnóstico, patogenia, terapêutica e controle. Brasília: Embrapa - SPI, 1996.

ROSATI, S.; PITTAU, M.; TOLARI, F.; ERRE, G.; KWANG, J. Genetic and antigenic characterization of cave (caprine arthritis-encephalitis virus) recombinant transmembrane protein. Veterinary Microbiology, v. 45, n. 4, p. 363-370, 1995.

SILVA, J.S.; CASTRO, R.S.; MELO, C.B.; FEIJÓ, F.M.C. Infecção pelo vírus da artrite encefalite caprina no Rio Grande do Norte. Arquivo Brasileiro de Medicina Veterinária e Zootecnia, v.57, n.6, p.726-731, 2005.

SOBRINHO, P.A.M.; RAMOS, T.R.R.; FERNANDES, C.H.C.; CAMPOS, A.C.; COSTA, L.M.; CASTRO, R.S. Prevalência e fatores associados à infecção por lentivírus de pequenos ruminantes em caprinos no estado do Tocantins. Ciência Animal Brasileira, Goiânia, v. 11, n. 1, p. 117-124, 2010.

THRUSFIELD, M.V. Transmissão e manutenção da infecção. In: Epidemiologia

Veterinária. 2. ed. São Paulo: Roca, 2004. p. $101-120$.

ZINK, M.C.; YAGER, J.A.; MYERS, J.D. Pathogenesis of Caprine Arthritis Encephalitis Virus. American Journal of Pathology, v. 136, n. 4, p. 843 - 854, 1990. 